\title{
Expression and characteristics of rice xylanase inhibitor OsXIP, a member of a new class of antifungal proteins
}

\author{
R.-J. SUN ${ }^{1}$, Y. XU' ${ }^{2}$, C.-X. HOU ${ }^{3}$, Y.-H. ZHAN ${ }^{2}$, M.-Q. LIU ${ }^{4}$, and X.-Y. WENG ${ }^{2 *}$ \\ College of Animal Science, Zhejiang University, Hangzhou 310058, P.R. China ${ }^{1}$ \\ College of Life Science, Zhejiang University, Hangzhou 310058, P.R. China ${ }^{2}$ \\ The Institute of Rural Development and Information Institute, Zhejiang Academy of Agricultural Sciences, \\ Hangzhou 310021, P.R. China ${ }^{3}$ \\ College of Life Science, China JiLiang University, Hangzhou 310018, P.R. China
}

\begin{abstract}
It has been hypothesized that xylanase inhibitors play important roles in plant defense against microbial pathogens. Currently, there is little information available about xylanase inhibitor OsXIP in rice and its gene expression. We cloned a xylanase inhibitor gene OsXIP from rice (Oryza sativa L. cv. Nipponbare) genomic DNA. To determine the function of OsXIP, we generated $O s X I P$-overexpressing transgenic rice plants. The transgenic plants had significantly higher OsXIP expression and showed enhanced defense response to Magnaporthe oryzae compared to the wild-type plants. The results also showed that the increased $O_{S} X I P$ expression was accompanied by the up-regulation of pathogenesisrelated genes. To clarify the OSXIP expression pattern, a ProOsXIP::GUS vector was constructed and transgenic plants were obtained. GUS staining results revealed that $O S X I P$ showed organ-specific expressions in rice plants. OsXIP was primarily expressed in the roots and in the veins, but it was weakly expressed in the leaves. Analyses of the $O s X I P$ expression in response to biotic and abiotic stresses indicated that it was drastically induced by biotic stresses and methyl jasmonate treatment. OsXIP, a member of a new class of antifungal proteins, may function as a barrier that prevents the cell wall degradation by xylanases excreted by fungal pathogens. The OsXIP was found to be a stressresponsive gene and it could take part in plant defense via a JA-mediated signaling pathway.
\end{abstract}

Additional key words: biotic stress, gene expression, Magnaporthe oryzae, methyl jasmonate, Oryza sativa.

\section{Introduction}

Xylanase inhibitors (XIP) inhibit endo- $\beta-1,4$-xylanase activity, which degrades plant cell walls. Plant cell wall is the first barrier against pathogen infection. When pathogens start degrading the plant cell wall components, plants are able to sense the loss of cell wall integrity and activate the defense signaling pathways (Bellincampi et al. 2014). Xylan is the major hemicellulose polymer in cell wall of cereals. To counteract xylan degradation by microbial endoxylanases, graminaceous monocots produce xylanase inhibitors (Moscetti et al. 2015). Previous reports have suggested that xylanase inhibitors protect plants from the unwanted hydrolytic effects of endogenous enzymes and from infecting micro-organisms (Beliën et al. 2007, Dornez et al. 2010). To date, three types of xylanase inhibitors have been identified in cereals: XIP (xylanase inhibitor protein)-type, TAXI (Triticum aestivum xylanase inhibitor)-type, and TLXI (thaumatin-like xylanase inhibitor)-type (Debyser et al. 1999, McLauchlan et al. 1999, Fierens et al. 2007). A number of studies have shown that different classes of xylanase inhibitors exhibit different effectiveness towards various xylanases (Goesaert et al. 2004, Fierens et al. 2007, Misas-Villamil and Van der Hoorn 2008, Tundo et al. 2015). Xylanases from Aspergillus niger and

Submitted 27 February 2017, last revision 4 November 2017, accepted 10 November 2017.

Abbreviations: GFP - green fluorescent protein; GUS - $\beta$-glucuronidase gene; IPTG - $\beta$-D-thiogalactoside; MeJA - methyl jasmonate; OsXIP - rice xylanase inhibitor; PR - pathogenesis-related; qPCR - quantitative polymerase chain reaction; WT - wild type..

Acknowledgements: This work was financially supported by the National Natural Science Foundation of China (Grant Nos. 30971702, 31271632, and 31672462), by research grants from the Science and Technology Department of Zhejiang Province, China (No. 2016C32086), and by the Zhejiang Provincial Natural Science Foundation of China (No. Y15C200013).

* Corresponding author; fax: (+86) 057188206485, e-mail: xyweng@zju.edu.cn 
Bacillus subtilis could be inhibited by TAXI-I (Fierens et al. 2003). Wheat xylanase inhibitors XIP-R1 and TAXI-I are also expressed in Escherichia coli, and wheat xylanase inhibitor XIP-R1 inhibits xylanases from Thermomyces lanuginosus, Trichoderma longibrachiatum, Trichoderma viride, Aureobasidium pullulans, and Aspergillus niger (Takahashi-Ando et al. 2007). Vasconcelos et al. (2011) reported that a chitinaselike XIP from Coffea arabica inhibits the germination of soybean Asian rust (Phakopsora pachyrhizi) spores. Tokunaga and Esaka (2007) revealed the existence of rice $X I P$-family genes.

Large economic losses may occur when crops succumb to fungal pathogen invasion. However, very few antifungal proteins have been reported to be xylanase inhibitors (Peng et al. 2013). Xylanase inhibitors are of a special significance because they resist pathogenic fungi in crops or they may affect the efficiency of microbial xylanases in biotechnological applications, such as cereal processing. Xylanase inhibitors constitute a new class of antifungal proteins, but there is currently little available information about xylanase inhibitors and xylanase inhibitor gene expression.

The aim of this study was to elucidate expression and function of $O S X I P$. A xylanase inhibitor gene $O s X I P$ from rice was cloned and expressed in Escherichia coli. The xylanase inhibition specificity of the recombinant OsXIP and the biochemical properties of this protein were also examined. The OsXIP overexpressing transgenic rice plants were generated and defense responses to Magnaporthe oryzae including expression of pathogenesis-related $(P R)$ genes were determined in $\mathrm{T}_{1}$ plants. Additionally, we constructed a Pro OsXIP::GUS vector and used transgenic rice lines to clarify the expression pattern of OSXIP and to investigate how OsXIP responded to stresses and stress-related phytohormones.

\section{Materials and methods}

Plasmids, chemicals, and strains: Cloning host strain Escherichia coli DH5 $\alpha$, expressing host strain E. coli BL21, and expressing vector pET-30a $(+)$ were all purchased from Invitrogen (Carlsbad, USA); the pMD19T vector was obtained from Takara (Tokyo, Japan); birchwood xylan was purchased from Sigma (St. Louis, MO, USA); and Thermomyces lanuginosus and Trichoderma longibrachiatum xylanases were purchased from Sigma-Aldrich (St. Louis, MO, USA).

Plants, growth conditions, and treatments: The rice (Oryza sativa L. cv. Nipponbare) wild-type (WT) and its transgenic lines were used. The seeds were germinated in water and then grown in a culture solution according to Wang et al. (2009) for $14 \mathrm{~d}$ in a growth chamber at a 14-h photoperiod, an irradiance of $1000 \mu \mathrm{mol} \mathrm{m} \mathrm{m}^{-2} \mathrm{~s}^{-1}$, day/ night temperatures of $28 / 18{ }^{\circ} \mathrm{C}$, and a relative humidity ranged between 76 and $94 \%$. For the expression pattern analysis, the various tissues of seedlings were collected at different stages during the growth period. These seedlings were also used for pathogen inoculation and methyl jasmonate (MeJA) treatments. The agronomic traits were measured at the plant maturity stage using plants that had been cultivated in an experimental field.

The fungal isolate used in the study was Magnaporthe oryzae strain KJ201, provided by the College of Agriculture and Biotechnology, Zhejiang University, which was virulent towards the rice japonica cultivars. Two-week-old rice seedlings were sprayed with $M$. oryzae at a concentration of $1.5 \times 10^{5}$ (spores) $\mathrm{cm}^{-3}$ containing $0.05 \%(\mathrm{v} / \mathrm{v})$ Tween-20 or with sterile water containing $0.05 \%$ Tween-20, which served as a control (Lee et al. 2001). The inoculated plants were moved to a dew chamber set at $28^{\circ} \mathrm{C}$ for $36 \mathrm{~h}$ and then were returned

to a growth chamber. The leaf tissues were harvested at $0,1,2$, and 3 d post-inoculation.

To analyze the OsXIP expression in the response to biotic and abiotic stresses, the $\beta$-glucuronidase (GUS) activities in the roots and shoots were measured in twoweek-old rice seedlings that had been subjected to $0.2 \mathrm{mM}$ MeJA, Nilaparvata lugens, wounding, low temperature $\left(8^{\circ} \mathrm{C}\right)$, or distilled water (control).

Molecular cloning: The rice genomic DNA was extracted according to the manufacturer's instructions (Invitrogen). The OsXIP sequence was amplified by PCR using rice genomic DNA as a template with primers 5'-ATGGCGCTTCGACGCCT'-3 (forward) and 5'-TCACAGGTGAGCCGTGAA'-3 (reverse), which linked with the EcoR I and Xho I sites, respectively. The PCR program consisted of preheating at $94{ }^{\circ} \mathrm{C}$ for 5 min, 30 cycles of $94{ }^{\circ} \mathrm{C}$ for $30 \mathrm{~s}, 60^{\circ} \mathrm{C}$ for $30 \mathrm{~s}$, and $72{ }^{\circ} \mathrm{C}$ for $1 \mathrm{~min}$, followed by extension at $72{ }^{\circ} \mathrm{C}$ for $10 \mathrm{~min}$. A DNA fragment of approximately $900 \mathrm{bp}$ was generated and cloned into the vector pMD19T. The clone that contained the resulting PCR product was transformed into $E$. coli strain DH5 $\alpha$.

Expression of OsXIP protein in Escherichia coli: The DNA sequence was amplified with primers from the pMD19T-OsXIP plasmid to obtain recombinant OsXIP protein. The amplified PCR product was digested and inserted into the pET-30a (+) vector (Novagen, Gibbstown, USA) at the EcoRI and XhoI sites. This expression vector was named pET30a-OsXIP. Then, pET30a-OsXIP was introduced into $E$. coli BL21. The transformants were screened on Luria-Bertani (LB) plates with $100 \mu \mathrm{g} \mathrm{cm}^{-3}$ kanamycin. The positive transformants 
were cultured in a liquid LB medium with $50 \mu \mathrm{g} \mathrm{cm}^{-3}$ kanamycin at $37{ }^{\circ} \mathrm{C}$ for $12 \mathrm{~h}$ and then induced with $\beta$-D-thiogalactoside (IPTG; $0.1 \mathrm{mM}$ final concentration) for $8 \mathrm{~h}$. The cells were harvested by centrifugation (10 $\left.000 \mathrm{~g}, 4{ }^{\circ} \mathrm{C}, 10 \mathrm{~min}\right)$, resuspended in McIlvaine's buffer $\left(0.1 \mathrm{M}\right.$ citric acid, $0.2 \mathrm{M} \mathrm{Na} \mathrm{NPO}_{4} ; \mathrm{pH}$ 6.0), sonicated, and centrifuged $\left(15000 \mathrm{~g}, 4{ }^{\circ} \mathrm{C}, 10 \mathrm{~min}\right)$. Electrophoresis was performed on $12.5 \%(\mathrm{~m} / \mathrm{v})$ sodium dodecyl sulfate-polyacrylamide gel (SDS-PAGE). The OsXIP fusion protein expressed by $E$. coli was digested with enterokinase after it had been purified using an Ni-NTA Spin kit (Qiagen, Hilden, Germany), according to the manufacturer's instructions. Then, the xylanase inhibitor activity was measured. The protein content was determined according to Bradford (1976). N-terminal protein sequencing was performed on an $492 \mathrm{cLC}$ protein sequencer (Applied Biosystems, Foster City, USA).

Vector construction and rice transformation: The method used to construct the transgenic vector (pTCK303-OsXIP) is shown in Fig. 1. The complete OSXIP coding sequence was amplified from the pMD19T-OsXIP plasmid with a pair of specific primers containing KpnI or $S a c$ I restriction sites (forward primer: 5'-GGGGTACCTCGCCGACGTCCCAGAAC-3'; reverse primer: 5'-CGAGCTCTTACGCTCGCAGGTGAGC CGTGAAG-3'). Then the PCR fragment was ligated to the pTCK303 vector, which contains the UBi-1 promoter, the reporter gene GUS (encoding $\beta$-glucuronidase), and the resistance gene hygromycin. The sequence from the -2122 to -1 fragments upstream of $O s X I P$ in the promoter:GUS construct was amplified from the rice genomic DNA by PCR. The fragments were then introduced in front of the GUS reporter gene in the PBI101GUS-plus vector (a derivative of PBI101.3 that carries the GUS plus sequence).

The OsXIP-over and Pro OsXIP::GUS constructs were introduced into Agrobacterium tumefaciens L. strain EHA105 by electroporation. Subsequent transformations were carried out using calli derived from the mature seeds of Oryza sativa cv. Nipponbare as described previously (Hiei et al. 1994, Weng et al. 2013). The transformed calli were selected on hygromycin-containing medium. The transgenic rice lines that had been transformed were recorded as $\mathrm{T}_{0}$. Their seeds were harvested from the panicles and the second generation was recorded as $T_{1}$. The transgenic rice $T_{1}$ lines were then used for further physiological and biochemical research.

Xylanase inhibitor activity: Xylanase inhibitor activity was determined using the 3,5-dinitrosalicylic acid method (Miller 1959). Xylanase inhibitor activity was determined by measuring the activity of different xylanases in the presence and absence of recombinant OsXIP according to the method of Tokunaga and Esaka (2007). Xylanase inhibition activities were determined in triplicate. The Thermomyces lanuginosus and Trichoderma longibrachiatum xylanases were purchased from SigmaAldrich. The extraction of proteins and determination of xylanase inhibitor activity in rice followed the method as described by Elliott et al. (2003).

RNA isolation, cDNA synthesis, and real-time quantitative PCR: Total RNA was isolated from the shoots and roots of rice (WT and transgenic seedlings) that had been subjected to different treatments using the miniBEST universal RNA extraction kit (Takara) according to the manufacturer's protocol. The cDNA was prepared using the PrimeScript first-strand cDNA synthesis kit (Takara). The real time qPCR was performed on a Light Cycler480 (Roche, Rotkreuz, Switzerland) using a $S Y B R^{\circledR}$ Premix Ex TaqTM kit (Takara). The rice actin gene Osactin (GenBank: AK101613.1) was selected as an internal standard. The qPCR assays for all the genes were performed as previously described (Weng et al. 2013). The protocol consisted of 35 cycles of $95^{\circ} \mathrm{C}$ for $5 \mathrm{~s}$ and $60{ }^{\circ} \mathrm{C}$ for $30 \mathrm{~s}$. The gene-specific primers are listed in Table 1 Suppl.

GUS staining and quantitative analysis: Plant tissues and organs were collected and stained in X-glucuronide dissolved in $10 \mathrm{mM}$ EDTA, $1 \mathrm{mM}$ potassium hexacyanoferrate, $0.1 \%(\mathrm{~m} / \mathrm{v})$ Triton $X-100$, and $100 \mathrm{mM}$ phosphate buffer at $\mathrm{pH} 7.0$ (at $37{ }^{\circ} \mathrm{C}$ ), followed by $95 \%$ $(\mathrm{v} / \mathrm{v})$ ethanol cleaning. The various tissues were observed with a Carl Zeiss LSM510 laser scanning system (http://www. zeiss.com/). Quantitative GUS activity was measured using the method described by Jefferson et al. (1987) with some modifications.

Subcellular localization: The 35SPro::OsXIP:GFP expression vectors were constructed by subcloning the full-length ORFs without terminators from OsXIP into the pCAMBIA1300-sGFP vector (Zhou et al. 2009). The resulting construct was transformed into Agrobacterium tumefaciens strain EHA105 and then introduced into Nicotiana benthamiana Domin leaves (Wroblewski et al. 2005). The leaves were observed with a confocal laser scanning fluorescence microscope (LSM 710, Carl Zeiss $A G$, Germany).

Statistical analysis: The enzyme activities were determined from three independent experiments. Analysis of variance was performed on the data, and significant differences from the control values were calculated by Duncan's multiple range test. 


\section{R.-J. SUN et al.}

\section{Results}

The gene encoding OsXIP localized on chromosome group 11 was isolated from rice genomic DNA. The OsXIP coding sequence was cloned into expression vector pET-30a(+) and placed in a frame with an $\mathrm{N}$-terminal extension that included a His-tag. The expressed protein was a fusion protein with 71 additional amino acids at the N-terminus of the vector. Protein expression in E. coli BL21 was induced by IPTG after $8 \mathrm{~h}$. A clear band with a molecular mass of about $35 \mathrm{kDa}$ was determined by SDS-PAGE analysis of the obtained fraction. The xylanase inhibitor activity toward xylanases from $T$. lanuginosus and $T$. longibrachiatum (Fig. 2A,B) indicated that the recombinant OsXIP had been purified.

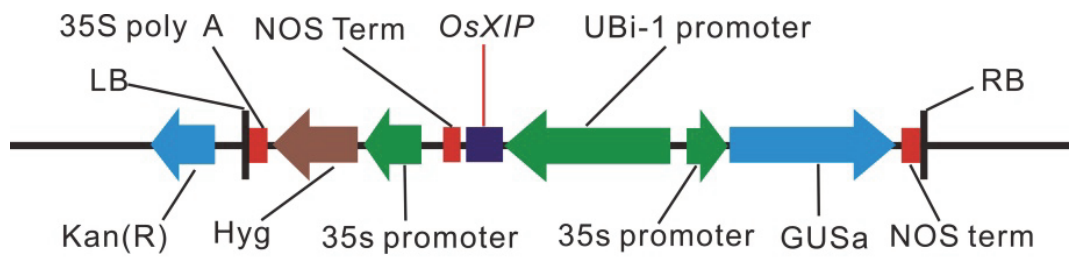

Fig. 1. The strategy for the construction of OsXIP-overexpressing vector.

Agrobacterium-mediated transformation produced $232 \mathrm{~T}_{0}$ plants overexpressing OsXIP construct. The independent transgenic rice lines were selected by PCR analysis using gene-specific primers for the hygromycin resistance gene. Southern blot analysis was used to further confirm the positive transformants and estimate the copy number of the integrated transgene in the positive transformants (Fig. 1 Suppl.). The results showed that at least four independent lines had higher OsXIP mRNA induction than the WT plants. The OsXIP expression in $T_{1}$ plants (14-d-old seedlings) were analyzed by real time qPCR, and the OsXIP expressions in transgenic lines Os- 2 and Os- 8 (with single copy integration) were 52.8 and 56.8 times higher than in the WT plants, respectively (Fig. $3 B$ ). So the Os-2 and Os-8 lines were chosen for further physiological and biochemical research.

The $\mathrm{pH}$ and temperature optima for xylanase inhibitor activity in transgenic rice were analyzed using xylanases from $T$. lanuginosus as the target enzymes. The optimal $\mathrm{pH}$ for xylanase inhibitor activity in the transgenic lines was similar, with activity peaking at $\mathrm{pH}$ 5.0. Furthermore, there was $80 \%$ activity between $\mathrm{pH} 4.0$ and 6.0 . The optimal temperature for OsXIP protein xylanase
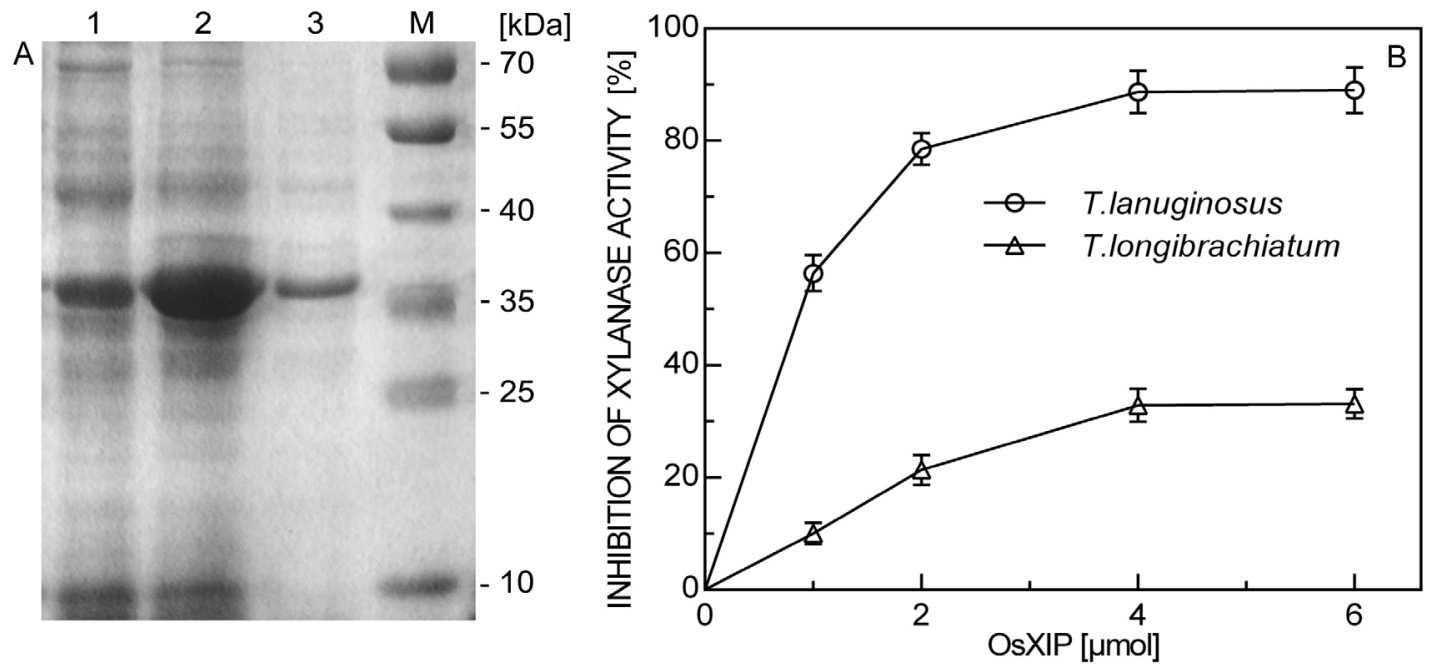

Fig. 2. SDS-PAGE and xylanase inhibitor activity of the recombinant OsXIP expressed in Escherichia coli BL21. A - SDS-PAGE of the protein fraction obtained from strains of E. coli BL21; the protein was stained with Coomassie brilliant blue. M - marker of proteins, lane 1 - crude protein extracts from control strain of $E$. coli containing pET30a-OsXIP vector, lane 2 - crude protein extracts from $E$. coli containing pET30a-OsXIP vector induced by IPTG after $8 \mathrm{~h}$, lane 3 - purified recombinant OsXIP expressed in Escherichia coli BL21. B - Xylanase inhibitor activity of recombinant inhibitor protein OsXIP. Xylanases were from Thermomyces lanuginosus and Trichoderma longibrachianum. The data represent means \pm SDs of three independent replicates. 
inhibition activity in the overexpressing transgenic rice and recombinant OsXIP lines was measured (Fig. 3A). The results showed that their inhibition activities were similar. It was rather low at $20-40{ }^{\circ} \mathrm{C}$, but then rapidly increased and reached a maximum at $60^{\circ} \mathrm{C}$.

The phenotype parameters were measured at plant maturity. The transgenic lines appeared to grow and develop normally. There were no significant differences in plant height, panicle length, and tiller and panicle numbers compared to non-transgenic (WT) plants (data not shown).

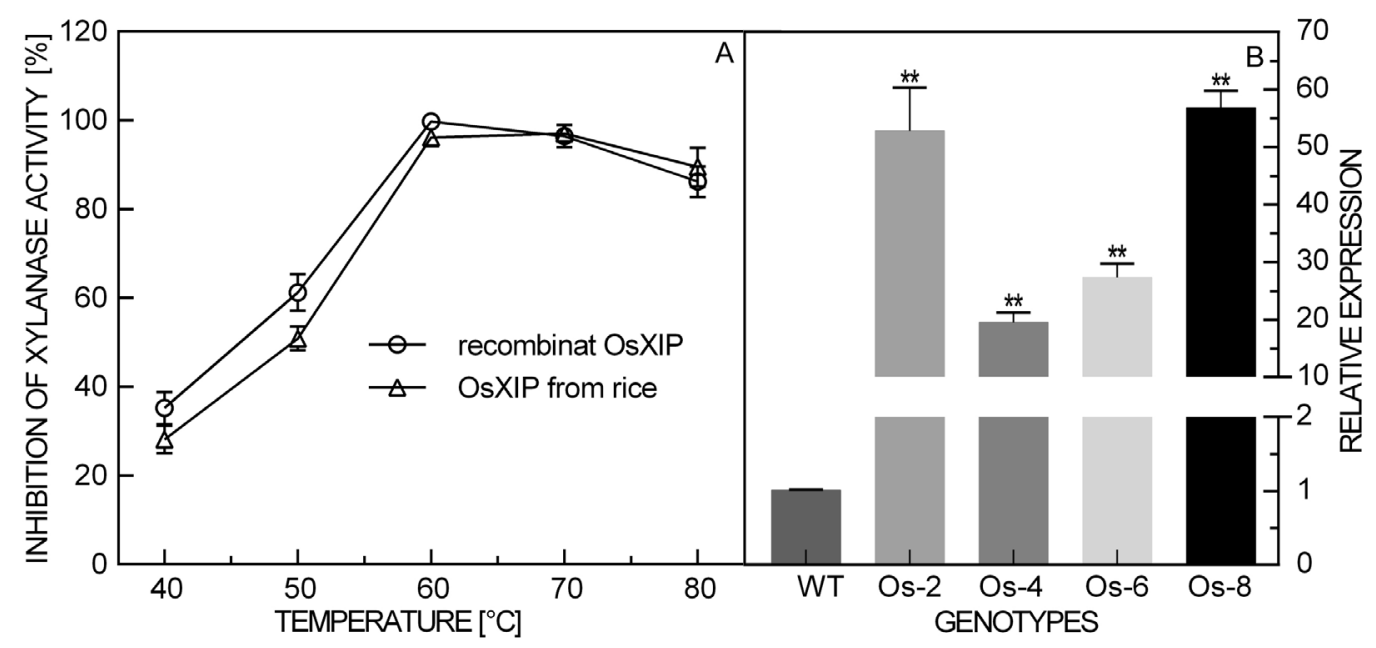

Fig. 3. Recombinant protein OsXIP and $O s X I P$ gene expressed in transgenic plants. $A$ - Effect of temperature on xylanase inhibitor activity. $B$ - Relative expression of OsXIP mRNA in wild type (WT) and overexpressing transgenic plants (Os-2, Os-4, Os-6, and Os-8). The data represent means \pm SDs of three independent replicates. In $B$ asterisks indicate statistically significant differences compared with wild type (WT) at $P<0.01$.

During pathogen infection, the transcription of the OsXIP gene in OsXIP-overexpressing transgenic plants increased, and the disease severity measured on the transgenic lines after infection with Magnaporthe oryzae KJ201 was significantly less than on the non-transgenic (WT) plants (Fig. 4C). The lesion number per leaf and the lesion size on the transgenic plants were significantly reduced (Fig. 4A,B). The transcription of the Pyricularia oryzae resistance-d2 (Pid2) gene was also measured. Compared with the WT, both the Os- 2 and Os- 8 plants showed an increase in the expression of Pid2 gene at $3 \mathrm{~d}$ after inoculation (Fig. 4D). The expressions of three pathogenesis-related protein $(P R)$ genes in OsXIPoverexpressing plants (Os-2 and Os-8) were also examined. After infection with $M$. oryzae KJ201, the expression of OsPR1 (PR protein1), OsPRIb (basic PR protein1), and $P R 4$ in the transgenic plants significantly increased compared to the WT plants (Fig. 4D).

The subcellular localization of the OsXIP protein was determined so that its role could be evaluated. We constructed a 35SPro::OsXIP::GFP fusion gene and transiently expressed the constructs in Nicotiana benthamiana leaves. Confocal laser scanning fluorescence microscopy revealed that GFP fluorescence from the fusion protein was restricted to the outer parts of leaf cells (Fig. 5). The result strongly suggested that OsXIP might be located in the apoplastic space.

In order to investigate the expression pattern of the
OsXIP gene, upstream DNA from the OsXIP gene (-2122 bp) in WT was PCR-amplified using specific primers and fused with the GUS reporter gene. This chimeric gene cassette was introduced into the WT plants via Agrobacterium mediated transformation. Histochemical staining for GUS activity in $T_{1}$ plants showed that OsXIP was expressed in the leaves of young seedlings, but was weakly expressed in leaves at the flowering stage (Fig. 6E,F). OsXIP was primarily expressed in the roots and the lemma, but not in the stamens (Fig. 6A,B,C,D). These results suggest that the OsXIP expression was tissue- and growth stage-specific.

Further, two-week-old seedlings were subjected to $0.2 \mathrm{mM}$ MeJA, $200 \mathrm{mM} \mathrm{NaCl}$, Nilaparvata lugens infection, wounding, low temperature $\left(8^{\circ} \mathrm{C}\right)$, or distilled water as control. Then, the GUS activities in the roots and shoots were measured (Fig. 7A,B). The responses of OsXIP to stress and stress-related phytohormones were studied by quantifying the GUS expression in the shoot and root tissues of the transgenic rice plants. The results showed that OsXIP expressions were considerably induced by $N$. lugens, wounding, and MeJA, and weakly induced by low temperature and $\mathrm{NaCl}$. Furthermore, OsXIP expression in the roots was significantly higher than in the leaves. The $N$. lugens induction process was very similar to that caused by wounding. These results suggested that OsXIP protein induction by $N$. lugens might occur via a wounding-mediated pathway. 

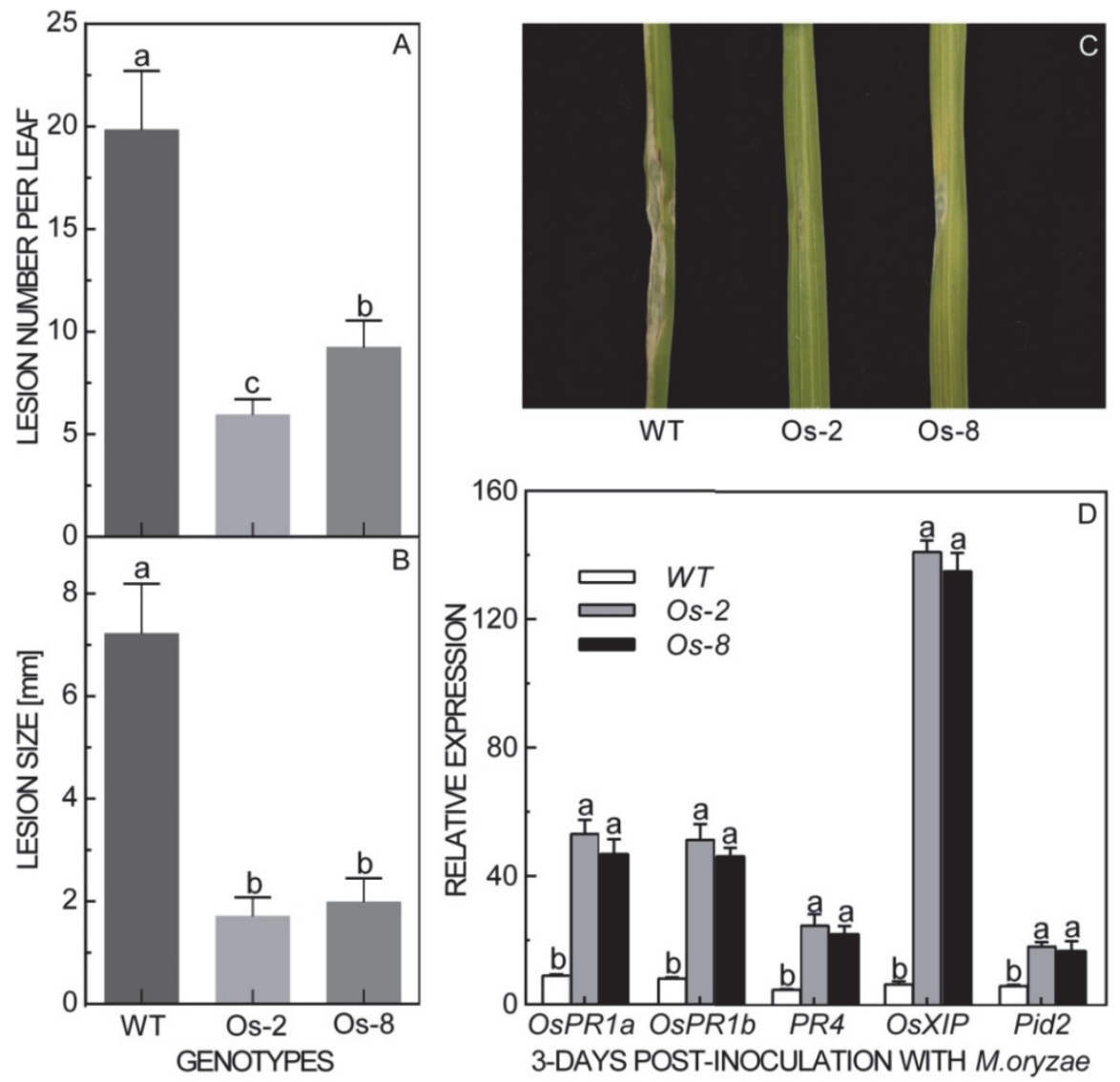

Fig. 4. The responses of $O s X I P$-overexpressing transgenic plants to Magnaporthe oryzae KJ201. A - Lesion number per leaf after inoculation with $M$. oryzae KJ201. B - Lesion size after inoculation with $M$. oryzae. $C$ - Rice blast symptoms on WT and $O s X I P$ overexpression Os-2 and Os- 8 plants infected with $M$. oryzae. $D$ - Relative expression of $O s X I P$ and $P R$ genes $(O s P R 1 a, O s P R 1 b$, $P R 4$, and Pid2) in WT, Os-2, and Os- 8 plants at $3 \mathrm{~d}$ post-inoculation with $M$. oryzae. The data represent means \pm SDs of three independent replicates; bars with different letters are significantly different at $5 \%$ level.

\section{Discussion}

In this study, we cloned a xylanase inhibitor gene encoding OsXIP from rice genomic DNA and expressed it in Escherichia coli (Fig. 2A). Recombinant OsXIP protein was active against xylanases from $T$. lanuginosus and T. longibrachiatum (Fig. 2B), which was consistent with a previous report that suggested that XIP-type xylanase inhibitors inhibit fungal xylanases (Flatman et al. 2002). Xylanase inhibitors are a new class of antifungal proteins and may function as a barrier that prevents cell wall degradation by xylanases from fungal pathogens (Tokunaga and Esaka 2007, Moscetti et al. 2013). Because of high recognition specificity between the different xylanase inhibitors and microbial xylanases, XIP- and TAXI-type xylanase inhibitors exhibit different effectiveness towards various microbial xylanases (Goesaert et al. 2004, Dornez et al. 2010, Tundo et al. 2015). Xylanase inhibitors, reducing the activity of microbial xylanases produced by pathogens, could play an important role in plant defense. Tundo et al. (2016) reported that a combined expression of multiple inhibitors in a single wheat genotype could reinforce the cell-wall barrier. They also revealed that pyramiding polygalacturonase inhibiting protein and a xylanase inhibitor TAXI-III improve plant resistance to Fusarium head blight. This improved resistance is likely due to synergistic or additive effects of different types of inhibitors on activities of cell wall degrading enzymes.

A more direct evidence of their involvement in plant defense has been reported by using transgenic plants. Moscetti et al. (2013) reported wheat transgenic plants overexpressing xylanase inhibitor gene TAXI-III could limit Fusarium graminearum infection. By loss-offunction analysis Tokunaga et al. (2008) demonstrated that OsXIP functions in defense against phytopathogens, but it is not involved in rice development per se. In our experiment, $O s X I P$-overexpressing transgenic rice plants were generated and the disease severity measured on the transgenic lines was less than in the WT plants after 

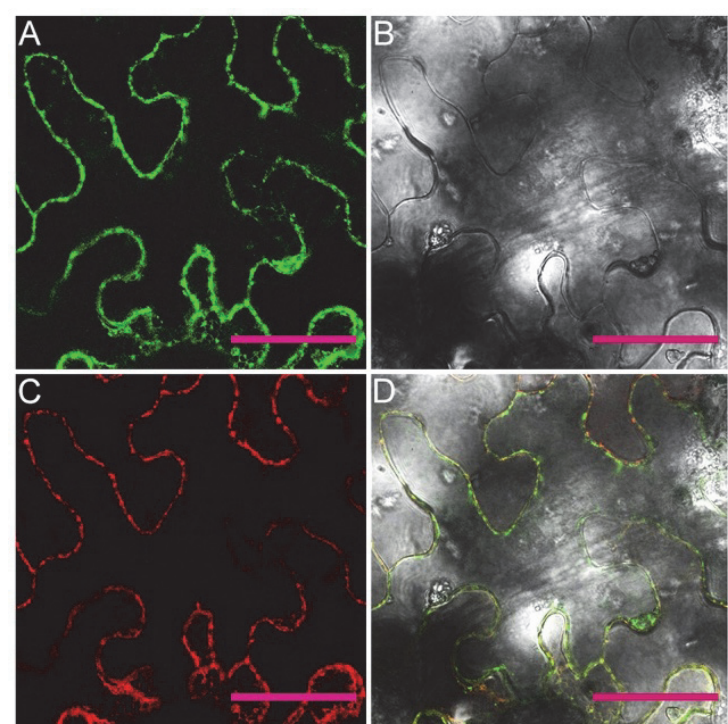

Fig. 5. Subcellular localization of OsXIP in Nicotiana

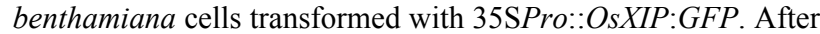
incubating for $48 \mathrm{~h}$, the transformed cells were observed under a confocal microscope. The photographs were taken for detecting GFP fluorescence $(A)$, under bright field $(B)$, and in combination (merge; $C$ ), respectively. Empty vector (pCAMBIA1300-GFP) was used as a control (D). Bars $10 \mu \mathrm{m}$. infection with Magnaporthe oryzae (Fig. 4). OsXIPoverexpressing transgenic plants displayed higher expressions of disease-resistant genes (Pid2), which may imply higher resistance. The Pid2 gene is a diseaseresistance gene with strong rice blast resistance and a broad resistance spectrum (Chen et al. 2006). We further investigated the mechanism of OsXIP mediated resistance by analyzing the expression of $P R$ genes in the transgenic lines after $M$. oryzae infection. PR proteins were produced in response to pathogen attacks, as a part of systemic acquired resistance. Expressions of $P R$ genes, such as OsPRla, OsPRIb, and PR4, were significantly enhanced in the $O s X I P$-overexpressing plants (Fig. 4D), suggesting that rice xylanase inhibitor OsXIP might alleviate symptoms of blast disease by increasing the expressions of $P R$ genes.

In cereals, xylanase inhibitors are encoded by a multigene family. Differential expression of individual genes has been demonstrated in various plants in response to environment cues. For example, the expressions of xylanase inhibitors Taxi-Ib/III and Taxi$\mathrm{IIb} / \mathrm{IV}$ in wheat leaves were induced after infection by the powdery mildew fungus Blumeria graminis (Igawa et al. 2004). Expressions of OsXIP and two other XIP-type xylanase inhibitors, riceXIP and RIXI, were
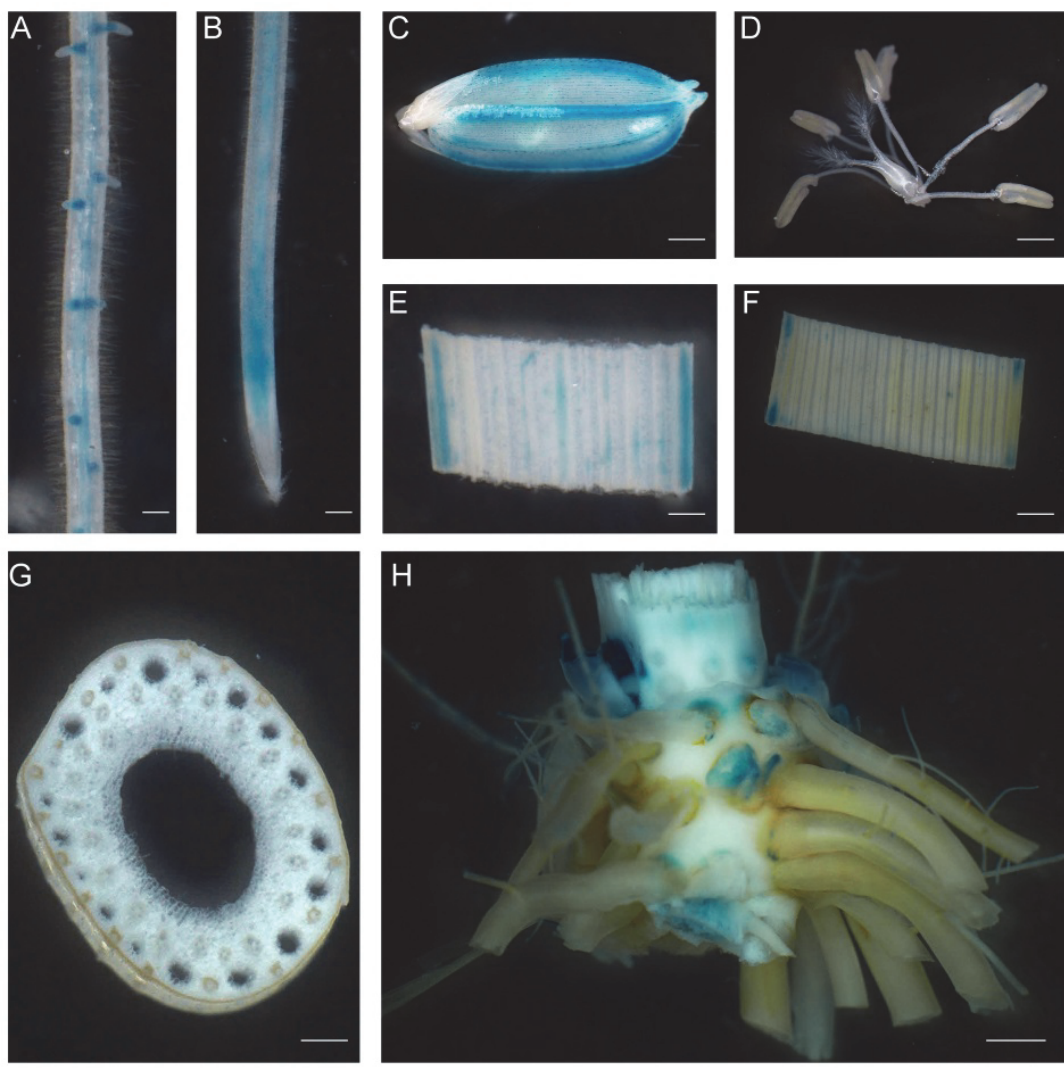

Fig. 6. Histochemical staining analysis of GUS activity in ProRIXI::GUS transgenic rice plants: $A$ - lateral root, $B$ - maturation, elongation, meristematic region, and root cap of primary root, $C$ - glume, $D$ - flower, $E$ - young leaf, $F$ - leaf in flowering stage, $G$ - stem, $H$ - root primordum. Bars - $100 \mu \mathrm{m}(A, B, E, F, 500 \mu \mathrm{m}(C, D, G)$, or $2 \mathrm{~mm}(H)$. 
detected in any organ during germination of rice seeds (Tokunaga and Esaka 2007). By Northern blot analysis, OSXIP and riceXIP expression were drastically induced by wounding and MeJA treatment in the rice root (Tokunaga and Esaka 2007). Our previous study revealed that pathogens could induce the expression of RIXI (Hou et al. 2015). In this study, we showed that in transgenic lines, Pro OsXIP::GUS was expressed in grains and other parts (Fig. 6). The expression of OSXIP in healthy roots and leaves of young seedlings was consistent with its function as a pre-existing defense barrier in plant tissues that are vulnerable to pathogen attack (Croes et al. 2009).

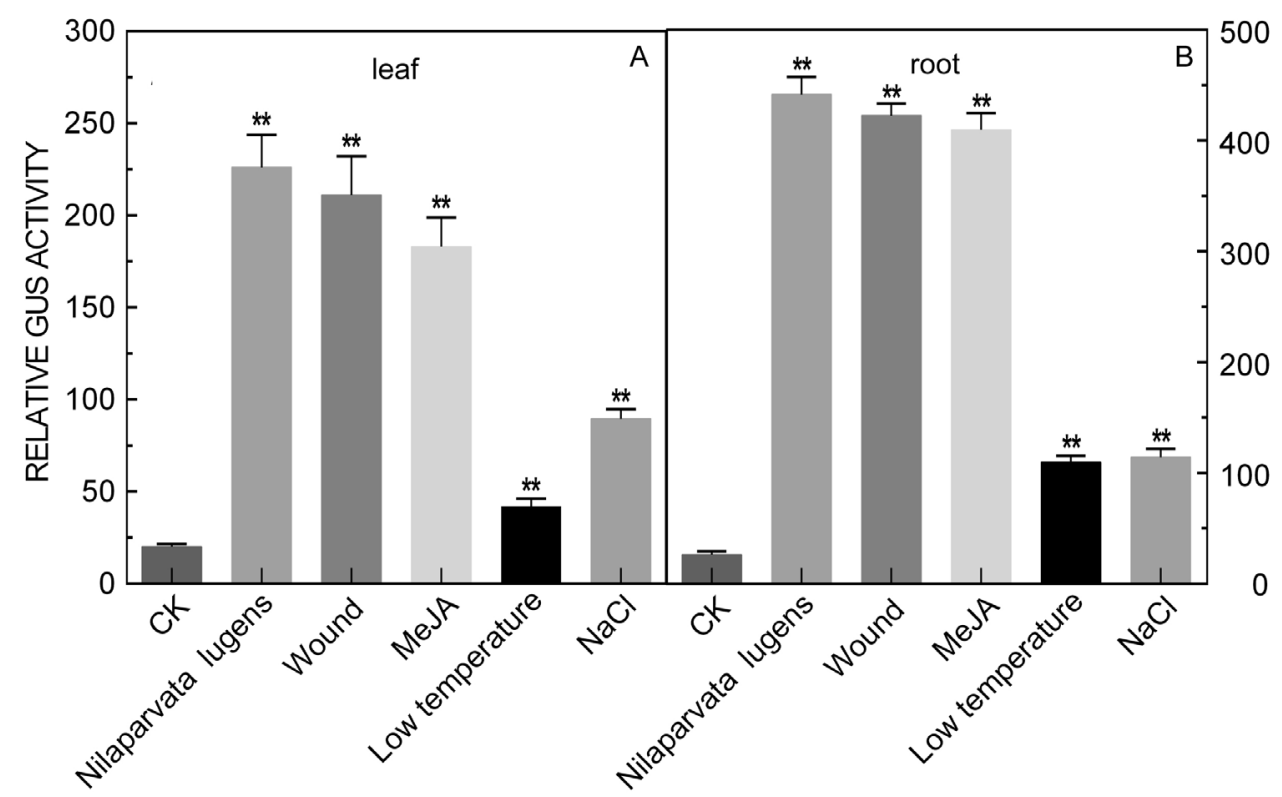

Fig. 7. GUS detection by quantitative fluorescence in leaf $(A)$ and $\operatorname{root}(B)$ of ProRIXI::GUS transgenic rice plants. The data represent means \pm SDs of three independent replicates. Asterisks indicate statistically significant differences between the treated and control plants at $P<0.01$.

The promoter region of a gene could provide valuable information about the factors regulating its expression. Several biotic and abiotic stress-responsive elements have been identified by a comparative analysis of cis-elements in the xylanase inhibitor gene promoters. We identified consensus cis-acting elements implicated in pathogenand wound-inducible gene expression, i.e., GCC-box and $\mathrm{W}$-box sequences in the 1.9-kb sequence upstream of the coding region of $O s X I P$ gene.

We used Pro OsXIP::GUS transgenic rice lines to investigate how $O S X I P$ responds to biotic and abiotic stresses. We revealed that $N$. lugens infestation, mechanical wounding, and MeJA treatment enhanced the expression of $O S X I P$, consistent with the results observed by Tokunaga and Esaka (2007) using Northern blot analysis. Furthermore, we showed that MeJA strongly induced the OsXIP expression in roots and mildly in leaves (Fig. 7). Meanwhile, the pattern of induction by
$N$. lugens was very similar to that by wounding. It is well known that jasmonic acid (JA) plays a key role in the regulation of the defense signaling network, which is activated when an invader is first detected (Pieterse et al. 2012); wounding causes a marked accumulation of JA, followed by the induction of a number of pathogenesisrelated genes (Kunkel and Brooks 2002, Turner et al. 2002). Besides reducing the activity of microbial xylanases produced by pathogens, OsXIP in cooperation with other pathogenesis-related proteins takes part in plant defense via a JA-mediated signaling pathway.

In conclusion, OsXIP as a member of a new class of antifungal proteins may prevent cell wall degradation by xylanases excreted by pathogens. OsXIP is a stressresponsive gene and may take part in plant defense via a JA-mediated signaling pathway. Overexpression of OsXIP results in increased PR gene expression as well as enhanced defense response to $M$. oryzae.

\section{References}

Bellincampi, D., Cervone. F., Lionetti, V.: Plant cell wall dynamics and wall-related susceptibility in plant-pathogen interactions. - Front. Plant Sci. 5: 228, 2014.

Beliën, T., Van Campenhout, S., Van Acker, M., Robben, J., Courtin, C.M., Delcour, J.A., Volckaert, G.: Mutational analysis of endoxylanases XylA and XylB from the phytopathogen Fusarium graminearum reveals comprehensive insights into their inhibitor insensitivity. Appl. environ. Microbiol. 73: 4602-4608, 2007.

Bradford, M.M.: A rapid and sensitive method for the 
quantitation of microgram quantities of protein utilizing the principle of protein-dye binding. - Anal. Biochem. 72: 248254, 1976.

Chen, X.W., Shang, J.J., Chen, D.X., Lei, C.L., Zou, Y., Zhai, W.X., Liu, G.Z., Xu, J.C., Ling, Z.Z., Cao, G., Ma, B.T., Wang, Y.P., Zhao, X.F., Li, S.G., Zhu, L.H.: A B-lectin receptor kinase gene conferring rice blast resistance. - Plant J. 46: 794-804, 2006.

Croes, E., Gebruers, K., Luyten, N., Delcour, J.A., Courtin, C. M.: The three classes of wheat xylanase inhibiting proteins accumulate in an analogous way during wheat ear development and germination. - J. Plant Physiol. 166: 12531262, 2009.

Debyser, W., Peumans, W.J., Van Damme, E.J.M., Delcour, J.A.: Triticum aestivum xylanase inhibitor (TAXI), a new class of enzyme inhibitor affecting breadmaking performance. - J. Cereal Sci. 30: 39-43, 1999.

Dornez, E., Croes E., Gebruers, K., De Coninck, B., Cammue, B.P.A., Delcour, J.A., Courtin, C.M.: Accumulated evidence substantiates a role for three classes of wheat xylanase inhibitors in plant defense. - Crit. Rev. Plant Sci. 29: 244-264, 2010.

Elliott, G.O., McLauchlan, W.R., Williamson, G., Kroon, P.A.: A wheat xylanase inhibitor protein (XIP-I) accumulates in the grain and has homologues in other cereals. - J. Cereal Sci. 37: 187-194, 2003.

Flatman, R., McLauchlan, W.R., Juge, N., Furniss, C., Berrin, J.G., Hughes, R.K., Manzanares, P., Ladbury, J.E., O’Brien, R., Williamson, G.: Interactions defining the specificity between fungal xylanases and the xylanase-inhibiting protein XIP-I from wheat. - Biochem. J. 365: 773-781, 2002.

Fierens, E., Rombouts S., Gebruers, K., Goesaert, H., Brijs, K., Beaugrand, J., Volckaert, G., Van Campenhout, S., Proost, P., Courtin, C.M., Delcour, J.A.: TLXI, a novel type of xylanase inhibitor from wheat (Triticum aestivum) belonging to the thaumatin family. - Biochem. J. 403: 583591, 2007.

Fierens, K., Brijs, K., Courtin, C.M., Gebruers, K., Goesaert, H., Raedschelders, G., Robben, J., Van Campenhout, S., Volckaert, G., Delcour, J.A.: Molecular identification of wheat endoxylanase inhibitor TAXI-I, member of a new class of plant proteins. - FEBS Lett. 540: 259-263, 2003.

Goesaert, H., Elliott, G., Kroon, P.A., Gebruers, K., Courtin, C.M., Robben, J., Delcour, J.A., Juge, N.: Occurrence of proteinaceous endoxylanase inhibitors in cereals. - Biochim. biophys. Acta 1696: 193-202, 2004.

Hiei, Y., Ohta S., Komari, T., Kumashiro, T.: Efficient transformation of rice (Oryza sativa L.) mediated by Agrobacterium and sequence analysis of the boundaries of the T-DNA. - Plant J. 6: 271-282, 1994.

Hou, C.X., Lv, T., Zhan, Y.H., Peng, Y.Y., Huang, Y.Y., Jiang, D.A., Weng, X.Y.: Overexpression of the RIXI xylanase inhibitor improves disease resistance to the fungal pathogen, Magnaporthe oryzae, in rice. - Plant Cell Tissue Organ Cult. 120: 167-177, 2015.

Igawa, T., Ochiai-Fukuda, T., Takahashi-Ando, N., Ohsato, S., Shibata, T., Yamaguchi, I., Kimura, M.: New TAXI-type xylanase inhibitor genes are inducible by pathogens and wounding in hexaploid wheat. - Plant Cell Physiol. 45: 1347-1360, 2004.

Jefferson, R.A., Kavanagh, T.A., Bevan, M.W.: GUS fusions: beta-glucuronidase as a sensitive and versatile gene fusion marker in higher plants. - EMBO J. 6: 3901-3907, 1987.

Kunkel, B.N., Brooks, D.M.: Cross talk between signaling pathways in pathogen defense. - Curr. Opin. Plant Biol. 5: 325-331, 2002.

Lee, M.W., Qi, M., Yang, Y.O.: A novel jasmonic acidinducible rice $m y b$ gene associates with fungal infection and host cell death. - Mol. Plant Microbe Interact. 14: 527-535, 2001.

McLauchlan, W.R., Garcia, C.M.T., Roza, M., Ravestein, P., Maat, J.: A novel class of protein from wheat which inhibits xylanases. - Biochem. J. 338: 441-446, 1999.

Miller, G.L., Blum, R., Glennom, W.E., Burton, A.L.: Measurement of methods for assay of xylanase activity. Anal. Biochem. 2: 127-132, 1959.

Misas-Villamil, J.C., Van der Hoorn, R.A.: Enzyme-inhibitor interactions at the plant-pathogen interface. - Curr. Opin. Plant Biol. 11: 380-388, 2008.

Moscetti, I., Faoro, F., Moro, S., Sabbadin, D., Sella, L., Favaron, F., D'Ovidio, R.: The xylanase inhibitor TAXI-III counteracts the necrotic activity of a Fusarium graminearum xylanase in vitro and in durum wheat transgenic plants. - Mol. Plant Pathol. 16: 583-592, 2015.

Moscetti, I., Tundo, S., Janni, M., Sella, L., Gazzetti, K., Tauzin, A., Giardina, T., Masci, S., Favaron, F., D'Ovidio, R.: Constitutive expression of the xylanase inhibitor TAXIIII delays Fusarium head blight symptoms in durum wheat transgenic plants. - Mol. Plant Microbe Interact. 26: 14641472, 2013.

Peng, L., Jack, H.W., Tzi, B.N., Vincent, S.M.H., Li, X.X.: A sorghum xylanase inhibitor-like protein with highly potent antifungal, antitumor and HIV-1 reverse transcriptase inhibitory activities. - Food Chem. 141: 2916-2922, 2013.

Pieterse, C.M., Van der Does, D., Zamioudis, C., Leon-Reyes, A., Van Wees, S.C.: Hormonal modulation of plant immunity. - Annu. Rev. Cell Dev. Biol. 28: 489-521, 2012.

Takahashi-Ando, N., Inaba, M., Ohsato, S., Igawa, T., Usami, R., Kimura, M.: Identification of multiple highly similar XIP-type xylanase inhibitor genes in hexaploid wheat. Biochem. biophys. Res. Commun. 360: 880-884, 2007.

Tokunaga, T., Esaka, M.: Induction of a novel XIP-type xylanase inhibitor by external ascorbic acid treatment and differential expression of $X I P$-family genes in rice. - Plant Cell Physiol. 48: 700-714, 2007.

Tokunaga, T., Miyata, Y., Fujikawa, Y., Esaka, M.: RNAimediated knockdown of the XIP-type endoxylanase inhibitor gene, OsXIP, has no effect on grain development and germination in rice. - Plant Cell Physiol. 49: 1122-1127, 2008.

Tundo, S., Kalunke, R. M., Janni, M., Volpi, C., Lionetti, V., Bellincampi, D., Favaron, F., D’Ovidio, R.: Pyramiding PvPGIP2 and TAXI-III but not PvPGIP2 and PMEI enhances wheat resistance against Fusarium graminearum. Mol. Plant Microbe Interact. 29: 629-639, 2016.

Tundo, S., Moscetti, I., Faoro, F., Lafond, M., Giardina, T., Favaron, F., Sella, L., D'Ovidio, R.: Fusarium graminearum produces different xylanases causing host cell death that is prevented by the xylanase inhibitors XIP-I and TAXI-III in wheat. - Plant Sci. 240: 161-169, 2015.

Turner, J.G., Ellis, C., Devoto, A.: The jasmonate signal pathway. - Plant Cell 14: S153-S164, 2002.

Vasconcelos, E.A.R., Santana, C.G., Godoy, C.V., Seixas, C.D.S., Silva, M.S., Moreira, L.R.S., Neto, O.B.O., Price, D., Fitches, E., Filho, E.X.F., Mehta, A., Gatehouse, J.A., 
Grossi-de-Sa, M.F.: A new chitinase-like xylanase inhibitor protein (XIP) from coffee (Coffea arabica) affects Soybean Asian rust (Phakopsora pachyrhizi) spore germination. BMC Biotechnol. 11: 14, 2011.

Wang, C., Ying, S., Huang, H., Li, K., Wu, P., Shou, H.: Involvement of OsSPX1 in phosphate homeostasis in rice. Plant J. 57: 895-904, 2009.

Weng, X.Y., Huang, Y.Y., Hou, C.X., Jiang, D.A.: Effects of an exogenous xylanase gene expression on the growth of transgenic rice and the expression level of endogenous xylanase inhibitor gene RIXI. - J. Sci. Food Agr. 93: 173179, 2013.

Wroblewski, T., Tomczak, A., Michelmore, R.: Optimization of Agrobacterium-mediated transient assays of gene expression in lettuce, tomato and Arabidopsis. - Plant Biotechnol. J. 3: 259-273, 2005.

Zhou, G., Qi, J., Ren, N., Cheng, J., Erb, M., Mao, B., Lou, Y.: Silencing OsHI-LOX makes rice more susceptible to chewing herbivores, but enhances resistance to a phloem feeder. - Plant J. 60: 638-648, 2009. 